\title{
LA ESCULTURA. ENGAÑANDO A LA GRAVEDAD
}

\author{
Gerardo Fuentes Pérez \\ Universidad de La Laguna; \\ Real Academia de Bellas Artes de San Miguel Arcángel, Santa Cruz de Tenerife \\ gfuentes@ull.es
}

\section{RESUMEN}

La escultura no es capaz de producir escenas tan complejas como lo hace la pintura, salvo el relieve que a través de los distintos planos crea la ilusión de la perspectiva y la narración. Y no se trata aquí de establecer criterios conceptuales a la manera de El Paragone, sino más bien la posibilidad de descubrir las capacidades constructivas de la escultura a la hora de concebir ciertas propuestas, como la representación de los contenidos por medio de la masa, la altura y la profundidad, es decir, de la tridimensionalidad. Ya en el pasado se esforzaron por obtener resultados tan complejos como el desafío a la gravedad (engañando a la gravedad), por medio del efecto óptico, del color, del movimiento, de la luz y de otros componentes. La Niké de Peonio, el Éxtasis de Santa Teresa de Bernini, la Anunciación de Günther o muchas de las obras realizadas por Canova, Orrico, Quinn, Bethencourt, etc., son muestras de esos alardes profesionales, dependiendo siempre de los materiales utilizados. La etapa barroca es la más fecunda en la producción de estos fines escultóricos, creando, como lo hizo Quirin Asam, auténticos montajes teatrales en los que los personajes parece que flotan.

Palabras Clave: escultura, gravedad, materiales, ilusión óptica.

\section{THE SCULPTURE. FOOLING GRAVITY}

\section{Abstract}

Sculptures are not capable of creating as complex scenes as painting does, except sculptural relief that creates the illusion of perspective and narration through the different planes. And it is not a question of establishing conceptual criteria in the manner of El Paragone, but rather discovering the constructive possibilities of sculpture in certain proposals, such as the representation of content through mass, height and depth, that is, the three-dimensionality. Already in the past, sculptors made an effort to obtain complex results such as the challenge to gravity (deceiving gravity), by means of optical effects, the colour, using movement, light and other components. The Niké by Peonio, the Ecstasy of Saint Teresa by Bernini, the Annunciation by Günther or many of the works by Canova, Orrico, Quinn, Bethencourt, etc. are samples of those professional boasting, always depending on the materials used. The Baroque period is the most fruitful stage in the production of these sculptural purposes, creating, as Quirin Asam did, authentic theatrical productions where the characters seem to float.

KEYWORDs: sculpture, gravity, materials, optical illusion.

DOI: https://doi.org/10.25145/j.histarte.2021.01.04

Revista de Historia Del Arte, 1; julio 2021, pp. 69-85; ISSN: e-2660-9142 


\section{ENGAÑANDO A LA GRAVEDAD}

A pesar de que se ha escrito sobre este aspecto de la escultura, aún sigue siendo un capítulo fascinante por las soluciones compositivas, técnicas y estéticas que aporta. Ya sabemos que la escultura no alcanzó las cotas conseguidas por la pintura, pues sus métodos siempre han permitido desarrollos de mayor calado, conquistando las principales áreas de los acontecimientos históricos, sobre todo. La escultura, en cambio, ha tenido que expresar con enormes esfuerzos esos mismos contenidos a través de la masa, del volumen, del espacio real y de otras condiciones físicas y mecánicas. La tridimensionalidad ofrece otros códigos que el espectador debe descubrir a la manera de exégesis o interpretación de lo que encierra la obra, dependiendo del material, del lugar y de otras tantas condiciones. La pintura relata un episodio concreto dentro de un espacio también concreto; la escultura tiene que despojarse de esas plusvalías para que la lectura pueda producir no tanto una interpretación sino un uso de esta, rompiendo los límites de la propia experiencia humana, es decir, dejándose llevar por lo que la obra propone desde sus entrañas expandiéndose hasta el infinito, pues para la escultura no hay límites, hay formas que prolongan realidades más allá de la razón. Podemos afirmar que la escultura es el acto creativo capaz de concentrar y transmitir uno o varios contenidos a la vez. La capacidad del artista es la encargada entonces de producir en el espectador recorridos transversales de los contenidos apenas verbalizables.

El pintor, con sus pinceles y paleta, organiza situaciones artificiosas que sugestionan las miradas, creando un mundo fascinante e irreal. Todos conservamos en el recuerdo esas grandes obras pictóricas de complicadas escenas repletas de personajes que se mueven en el espacio; esos temas alegóricos, civiles o religiosos, que cubren altas techumbres palaciegas, o esos amplios lienzos que recogen enseñanzas simbólicas, morales y triunfalismos patrios. Solo citar a manera de ejemplo La Paz y la Justicia, del italiano Corrado Giaquinto (1703-1766), conservada en el Museo del Prado (Madrid), que ha producido bastante literatura y que aquí deseamos citar el estudio que de esta obra llevó a cabo Jesús María González de Zárate (1987), aunque bajo la mirada de la emblemática. Aquí, la sucesión de colores, los contrastes, las tonalidades, las líneas que determinan diversos conjuntos, organizan un escenario en el que los personajes flotan en medio de cúmulos de nubes, produciendo una sensación de grandeza inalcanzable. Sin embargo, convertir esta representación alegórica en escultura supone hacer un ejercicio en el que entran a formar parte determinados cánones y fórmulas de carácter estético, estableciendo otros planteamientos y parámetros; ¡cómo transformar los presupuestos pictóricos en materia volumétrica sin perder ni un ápice del mensaje?, ¿cómo transmitir la sensación de ingravidez de los citados personajes a pesar de encontrarse sentados sobre las revoltosas nubes? Este propósito ya estuvo en la mente de los escultores de la Grecia clásica. Tal vez el ejemplo más interesante y representativo es sin lugar a duda la conocida Victoria del escultor Peonio (fechada en el 425 a.C.), hoy en el Museo Arqueológico de Olimpia (Grecia). Esta Victoria o Niké, realizada en mármol de Paros y considerada la más antigua de la que se tiene noticia, nos habla del conocimiento y dominio de los escultores griegos ya en plena etapa clásica. 


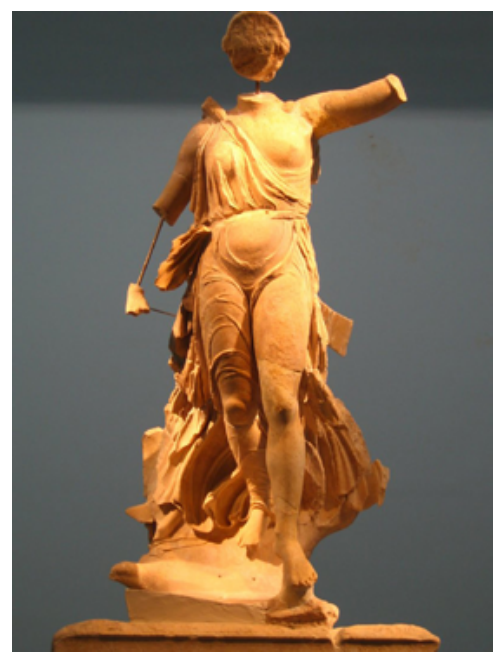

Fig. 1. Peonio de Mende, Niké, h. 425 a. C., $215 \times 75$ cm, Museo Arqueológico, Olimpia, Grecia. https://museum.classics.cam.ac.uk/collections/casts/nike-paionios,

consultado el día 12 de febrero de 2021.

El trabajo del mármol como material preferido permitió llegar a resultados casi impensables. Hoy tanto alumnos de Historia del Arte como cualquier otro espectador que contemple esta Victoria (en el propio museo o a través de imágenes impresas) no dejan de sorprenderse, de admirar la osadía del escultor. Es una lástima que no conozcamos con seguridad más obras de Peonio para llegar a tener una amplia dimensión no solo de su propia producción sino también de los programas, encargos, informaciones y conocimientos técnicos sobre escultura. La inscripción localizada en la base de la misma nos desvela el nombre del autor y las razones de su ejecución, dando ya referencias de ello el historiador y viajero Pausanias (c. 110180) en su obra Descripción de Grecia (libro v). En general, las representaciones de Victorias, como la de Samotracia (190 a.C.), aparecen bien ancladas en la base gracias al tumulto de pliegues que sirven de sostén a todo el conjunto, recurso empleado en los talleres grecorromanos para poder mantener erguidas estas enormes esculturas marmóreas. A veces se consigue añadiendo elementos variados que pertenecen al discurso temático, como animales, troncos de árboles, textiles, etc., aligerando así la sensación de pesadez del material. En realidad, se trata de un efecto óptico, de una ilusión que no deja de tener una alta dosis de teatralidad. En este caso, la deidad irrumpe con fuerza en la escena, como una aparición, confirmando el triunfo sobre los enemigos. Los pliegues se agitan debido a la rapidez de movimiento, mientras las alas se despliegan para amortiguar la llegada, el aterrizaje. El triunfo y la gracia vienen de lo alto, y las nikés aceleran su marcha. En Samotracia, la victoria acaba de llegar afianzando sus dos pies sobre el suelo. En cambio, Peonio, utilizando iguales procedimientos introduce el concepto tiempo-espacio, dejando al personaje sus- 
pendido, o haciéndonos creer que está suspendido, para lograr el movimiento final. La tensión no se centra en la distribución de los pliegues que son la base de todo el estudio, sino en la habilidad de producir en la mirada del espectador la sensación de que los pies aún no han tocado la tierra. Por tanto, no es un vuelo agitado, violento, pesado, sino todo lo contrario, suavizado por la necesidad del frenado que supone una irrupción de estas características.

Es importante tener en cuenta que el mármol, a pesar de su naturaleza maciza, compacta (no olvidemos que es una piedra), es bastante dúctil, muy maleable, de poca resistencia a los abrasivos, de modo que el escultor puede llegar a resultados insospechados, y no hace falta mencionar algunos de ellos para comprobarlo (Praxíteles, Miguel Ángel, Bernini, Canova, Thorvaldsen, etc.); en ocasiones se trata más bien de llegar a demostrar la capacidad profesional y el dominio de los materiales, poniéndose al servicio de lo narrativo. Por eso, Peonio se ajusta al momento del encuentro de la victoria con los vencedores. Los sorprende. Es un recurso muy usado por muchos artistas para determinar el trasfondo del discurso. La pintura alardea de este procedimiento, siendo la representación de los ángeles la más común, sobre todo la del arcángel san Gabriel en la escena de la Anunciación, que guarda un claro paralelismo con las nikés de la Grecia clásica. En general, el pintor resuelve la escena de tal manera que se pueda percibir todo el relato, atendiendo a las noticias facilitadas por san Lucas, el único que lo incluye en su Evangelio (1,26-38) ${ }^{1}$. En este caso, el arcángel se sitúa de pie frente a la Virgen María, en actitud dialogante, sin titubeos, con ambos pies sobre el suelo de la estancia, con absoluta firmeza en la comunicación del mensaje y siempre rodeado de nubes como signo del carácter divino del acontecimiento. Recordar, al menos, la encantadora obra de Agustino Masucci (1690-1758), que se halla en el Statens Museum for Kunst (Copenhague. Dinamarca); aquí, Nuestra Señora se muestra atenta a la conversación mantenida con el arcángel. Pero otras veces, el pintor lo representa en el preciso momento de irrumpir inesperadamente en el aposento, sin diálogo aparente. Muy despacio, y para no perturbar los pensamientos de María, poco a poco deja caer sus pies, pero sin llegar siquiera a rozar la tierra, como gesto de la dimensión sobrenatural de Dios. Es un personaje que viene de lejos, de lo Alto, y no pertenece al mundo de los humanos. Contamos con numerosísimos ejemplos en los que se narra este momento tan concreto y espacial, como el lienzo de Luca Giordano (1634-1705), perteneciente al Museo Metropolitano de Nueva York, o el realizado por Eustache Le Sueur (16171655), conservado en el Museo del Louvre (París), entre otros muchos. Aquí la persona de María se siente sorprendida, en actitud de recogimiento, pues aún no acaba de dar crédito a lo que está sucediendo. En esta obra, san Gabriel parece recordar esas Victorias del pasado, batiendo las alas para mantenerse aún en el aire. La Victoria viene también de lejos, del Olimpo, no solo para compartir el triunfo, sino también para expresar la gratitud y la protección de los dioses. Sin embargo, la escul-

\footnotetext{
1 Solo san Mateo (1, 18-19) lo menciona. Los restantes, san Marcos y san Juan, prescinden de este acontecimiento.
} 


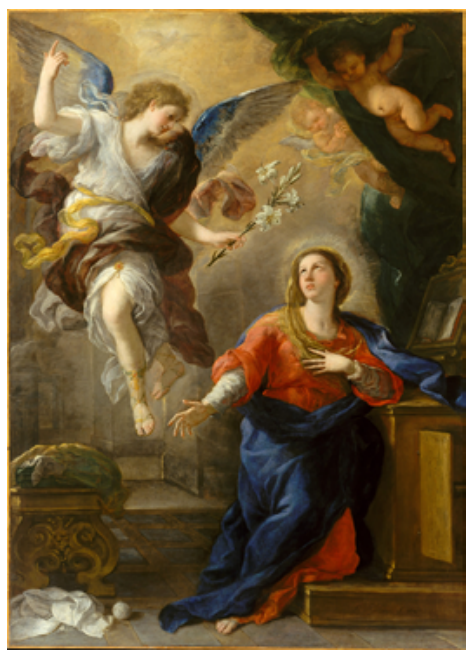

Fig. 2. Luca Giordano, La Anunciación, 1672, $236 \times 170 \mathrm{~cm}$, Museo Metropolitano, Nueva York, Estados Unidos. https://www.metmuseum.org/art/collection/search/436502, consultado el día 12 de febrero de 2021.

tura, a pesar de las dificultades que el mencionado pasaje evangélico produce, no ocultó sus capacidades para producir y expresar la misma escena y las mismas sensaciones. Y nos referimos a una de las obras más sobresalientes del rococó bávaro, a la ejecutada por el máximo representante de aquella escuela, Ignaz Günther (17251775), un artista que trabajó la madera policromada, una especie de Montañés alemán, que llegó a realizar numerosas esculturas de carácter religioso para muchas iglesias, monasterios y oratorios privados de Alemania, especialmente para la zona sur de credo católico.

En la abadía de Weyarn (Baviera, Alemania), entre muchas piezas llevadas a cabo con distintos materiales (mármol, madera, estuco, metal, etc.) se encuentra una de las piezas clave para entender este planteamiento: La Anunciación del citado escultor alemán. Bien es cierto que estamos en pleno rococó, una manifestación muy representativa del arte en Baviera, y que, como afirma Elio Franzini (2000), «el sentimiento, la pasión, lo sublime, el genio, la fantasía se encuentran en el centro de la ciencia» (151), y no deja de ser un elogio del exceso. Exceso para conseguir la convicción a través de artificios que a veces se llega al paroxismo, ayudado, qué duda cabe, por los materiales utilizados, pues ya no es el mármol el que determina los modelos y formatos de la producción escultórica; ahora intervienen otros elementos como la madera, policromada o no, y el yeso, sobre todo, muy dócil para soluciones rápidas y efectistas. Ahora la escultura se convierte en arquitectura o la arquitectura en escultura, pues cuando nos encontramos en el interior, por ejemplo, de una iglesia bávara, difícilmente podemos establecer la división entre un género y el otro, ya que los personajes allí representados parecen salir de las cornisas, de los techos, de 


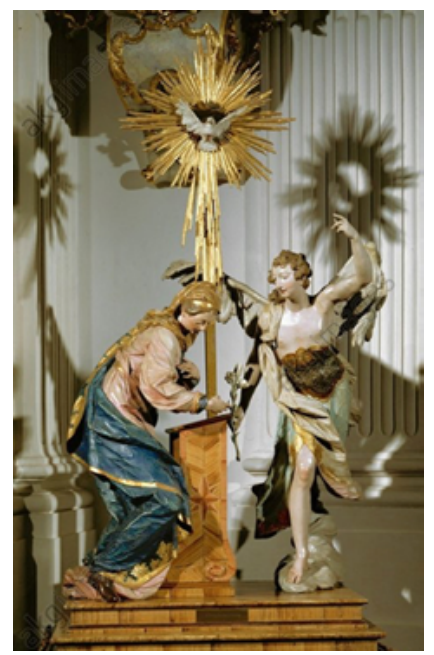

Fig. 3. Ignaz Günther, La Anunciación, 1763, $177 \times 105 \times 70 \mathrm{~cm}$, Museo parroquial, Weyarn, Baviera, Alemania. https://www.britannica.com/biography/Ignaz-Gunther, consultado el día 12 de febrero de 2021.

los púlpitos y retablos. Personajes que se agitan y que caen al vacío. Todo es movimiento, pero no al gusto del barroco más reposado y solemne; es el movimiento al servicio del placer visual. Tanto las esculturas incorporadas a la arquitectura como las exentas participan de estos mismos principios estéticos. Así, la referida Anunciación no es otra cosa que reflejo de aquellos programas que buscaban nuevos resultados narrativos, echando la mirada al arte clásico que entonces comenzaba a ser descubierto gracias a las excavaciones llevadas a cabo por expertos científicos, sobre todo en Italia (Pompeya, Herculano, etc.), y que el erudito alemán Winckelmann (1717-1768) dispuso que todo lo encontrado debía ser clasificado, ordenado y publicado por medio de método crítico. Los modelos griegos y romanos fueron ahora los parámetros del arte, de modo que la representación de ángeles viene a ser un reflejo de los apolos, adonis y demás.

El arcángel san Gabriel de Ignaz Günther es un joven efebo que recuerda sobremanera los juveniles y sensuales dioses de Praxiteles (395-330 a.C.), y que su contemporáneo Francisco Salzillo (1707-1783) también lo plasmó en el ángel de la Oración del Huerto (Murcia). Para Ignaz Günther estos planteamientos no le eran desconocidos. Su formación en los talleres de Johann Straub (1704-1784), de Paul Egell (1691-1752) y de otros más le permitió adquirir dominio y conocimiento de los lenguajes, propuestas y soluciones. Hay que tener muy presente a la hora de estudiar la producción de este escultor que el material utilizado para sus obras no fue básicamente el mármol. Fueron materiales más vulnerables (madera, yesos, etc.) con los que hizo realidad su discurso escultórico. La madera proporcionaba unos resultados más cálidos, muy matizados, al alcance siempre del espectador tanto en su 
comprensión volumétrica como emocional. De ahí que Günther, en un alarde de profesionalidad, ejecutó su Anunciación con un carácter más bien pictórico, lejos de los estereotipos convencionales. Ambos personajes, Nuestra Señora y el arcángel, se encuentran inscrito en un triángulo isósceles cuyo eje central viene determinado por uno de los rayos que componen el sol que envuelve al Espíritu Santo, y que finaliza en el reclinatorio donde se encuentra la Virgen María en actitud orante. La influencia de los patrones italianos, sobre todo genoveses y napolitanos, se deja entrever en la propia composición, muy gestual, en la que san Gabriel se sitúa de frente, como sujeto activo, de pie, dominando toda la escena de una manera absoluta. Como la Niké de Peonio, los pies no acaban de llegar al suelo; el derecho se adelanta con paso de danza, apoyado sobre unas nubes muy planas para no restarle nitidez al acontecimiento evangélico. El movimiento en balanceo se ha conseguido gracias a artificios muy engañosos, apenas perceptibles, pero que responden a una necesidad constructiva de la obra: un perno interior avanza por toda la pierna y los pliegues de la parte posterior de la vestimenta descansan sutilmente en el respingo de nubes. La situación de ambos brazos afianza el equilibrio de la obra, así como el inquietante revuelo del atuendo dirigido hacia atrás producido por la velocidad del mensajero celestial. La policromía, de tonos suaves y aporcelanados, contribuye a crear ese ambiente intimista propio del Rococó. Incluso la Virgen María produce la sensación de que se desploma ante la presencia inesperada del arcángel. No se encuentra arrodillada con firmeza, sino que sugiere una situación de éxtasis.

No cabe duda de que en esta extraordinaria obra, de composición efectista, se aprecia sobremanera la influencia de autores italianos como, por ejemplo, la de Lorenzo Bernini (1598-1680), el gran escenógrafo del Theatrum Sacrum que hizo de Roma un enorme escenario. Por eso todo cambia. Por eso la escultura tiene que producir movimiento, no quietud, sensaciones, seducciones y capacidad para integrar todas las emociones a la vez. El movimiento tiene que abordar hasta las razones más sorprendentes por muy artificiosas que fueran. El teatro barroco ayudó en este sentido a que la escultura se convirtiera en actores, en actores casi vivos, a través de muchos recursos. Las complicadas tramoyas, los cambios bruscos de decorados, bambalinas, candilejas, música, etc., fascinaron a un público ansioso de perderse en los secretos de la vida. El mismo Bernini tuvo un destacado protagonismo en el teatro como director, actor, constructor de tramoyas, maquinarias complicadas que producían los cambios de decorados, diseñador de proyectos para óperas, etc. Su hijo, Domenico Bernini (1657-1723), el benjamín de diez hermanos, historiador y biógrafo, publico en 1713 la vida de su padre, en la que nos informa de esta interesante faceta poco conocida, pero fundamental para comprender, en parte, las escénicas composiciones (Bernini 2018). No es extraño encontrarnos con escultores, pintores y arquitectos que en un momento de su vida sintieron la necesidad de zambullirse en las aguas de la farándula con el propósito de conocer los mecanismos internos del teatro como ayuda a sus posteriores trabajos artísticos.

Nuestro escultor Ignaz Günther se envolvió de todo este ambiente contemplando también los conjuntos de los hermanos Asam, una saga de artistas que se ocuparon de diversas actividades básicamente en la región de Baviera. Uno de ellos, Egid Quirin Asam (1692-1750), realizó elocuentes y complicados proyectos escéni- 


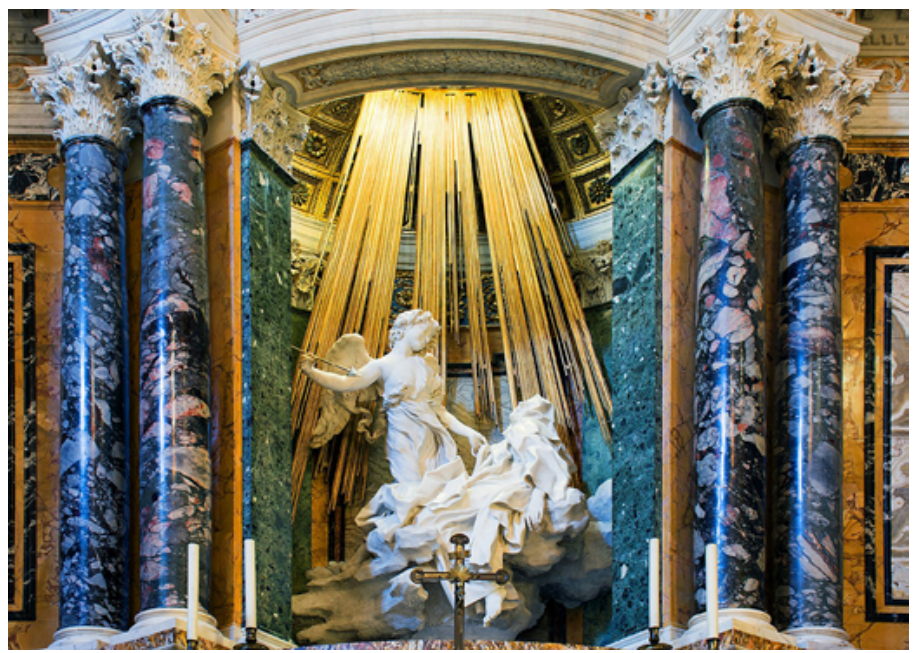

Fig. 4. Gian Lorenzo Bernini, Extasis de santa Teresa, 1647-1652, $350 \mathrm{~cm}$, Iglesia de Santa María de la Victoria, Roma, Italia.

https://www.lacamaradelarte.com/2017/09/extasis-de-santa-teresa-gian-lorenzo.html, consultado el día 12 de febrero de 2021.

cos para determinadas iglesias del lugar, como su conocida Asunción del monasterio benedictino de Rohr, inspirada, qué duda cabe, en las composiciones berninescas que él mismo conoció durante su viaje a Roma en 1711 junto a su hermano el arquitecto Cosmas Damian (1686-1739). La aplicación de yesos (a cierta distancia se confunde con mármol), la madera y otros materiales frágiles aligera considerablemente todo el enorme parapeto escultórico, en medio de un atrevido planteamiento teatral en el que domina el ilusionismo. Todo flota. El personaje de María, que es llevada a los cielos por dos ángeles, pende de la parte alta del gran camerino como si de un escenario se tratara, lográndose así la sensación de ingravidez, acentuada aún si cabe por los alargados fajines desatados que vuelan de un lado a otro. Los apóstoles, junto a la tumba vacía de la Virgen, gesticulan como actores en una tragedia griega. Una representación muy próxima a sus homólogas en versión pictórica.

Hay que reconocer que los materiales empleados ayudan notablemente a lograr ciertos objetivos en las composiciones, como la madera, el yeso, la arcilla, etc., además de la policromía. Pero cuando se trata de trabajos en piedra, especialmente en mármol, el escultor se ve obligado a crear la sensación de ingravidez por medio de ciertos procedimientos, pues le falta el color y todo el aparataje de la composición. Tiene que sugerir la morbidez, el vacío, la ligereza, los contrastes e, incluso, la propia policromía. La naturaleza del mármol es un vehículo para que el espectador traspase los límites establecidos por la volumetría. Es el caso del extraordinario conjunto del Éxtasis de santa Teresa, que se puede admirar en la capilla Cornaro, abierta en la iglesia de Santa María de la Victoria (Roma) entre 1644 y 1652. En este 
espacio, Bernini desplegó todo su saber arquitectónico, pictórico, escultórico y escénico, pues la concibió como un gran salón teatral, con palcos en los que se encuentran esculpidos el citado cardenal Cornaro, miembros de su familia y cardenales, como invitados excepcionales. Los mármoles de colores, la composición arquitectónica, las perspectivas y la luz crean una atmósfera mística. Y en el templete central, un amago de embocadura teatral, aparece el principal acontecimiento de todo este asunto: santa Teresa en el momento más sublime de la unión con Dios por el amor. Le acompaña el ángel que se dispone a lanzar la flecha (Amor de Dios) que atravesará su corazón, según lo relata ella misma en El libro de la vida:

Vía un ángel cabe mí hacia el lado izquierdo en forma corporal [...]. Viale en las manos un dardo de oro largo [...]. Este me parecía meter por el corazón algunas veces, y que me llegaba a las entrañas. Al sacarle, me parecía las llevaba consigo y me dejaba toda abrasada en amor grande de Dios. No es dolor corporal sino espiritual, aunque no deja de participar el cuerpo algo, y aun harto (Jesús 2007).

Bernini se arriesgó a representar precisamente ese momento trascendental de la santa de Ávila. No se conformó con llevar a cabo una escultura convencional, sino que se arriesgó a resolver este asunto como lo hubiera hecho la pintura -caso de Francesco Fontebasso (1707-1769), Budapest-, sin problema alguno. El mármol tiene que producir la sensación de ligereza, sin gravedad, a pesar de su masa y monocromía. Para Bernini ya no había secretos. Superaba los 50 años de edad y había producido el grueso de la obra, entre las que destacamos el Rapto de Proserpina (1621-1622) de la Galería Borghese (Roma), en la que el dramatismo del movimiento había alcanzado sus propósitos estéticos, efectistas, sensuales y mecánicos.

A pesar de la solidez de la pieza marmórea, Bernini logró imprimirle no solo un carácter pictórico por la propia composición y dinamismo, sino también reducir la sensación de carga que transmite la masa del material. La colocación de santa Teresa que se desvanece ante la presencia divina, el juego de pliegues a base de amplios ángulos y la ingenuidad del ángel, situado en diagonal, producen una cierta ligereza de las formas y volúmenes. La experiencia de fe de este artista, el conocimiento que tenía de los Ejercicios Espirituales de san Ignacio de Loyola y su formación religiosa le llevaron a plasmar la máxima aspiración espiritual en esta obra. Y he aquí su extraordinario alcance como artista: convertir el mármol, aparentemente frío y distante, en materia cálida y cercana, de superficie incluso táctil. Todo el conjunto se encuentra "suspendido tras la arquitectura sobre una nube algodonosa, bañado en luz, como si a pesar de su realismo fuera nuestra propia visión beatífica» (Hibbard 1982), desafiando a la propia gravedad, en una especie de levitación que Bernini intensifica dejando suspendido el pie izquierdo, produciendo así la impresión de que todo el cuerpo permanece elevado, completamente laxo, para indicar asimismo que lo que está sucediendo no es por causa humana, sino divina. A pesar de que esta obra sirvió de inspiración para muchos artistas que abordaron este pasaje de la vida de santa Teresa, Bernini no fue tan original en la concepción del diseño, pues el modelo lo encontró en un lienzo de Giovanni Lanfranco (1582-1647) que representa el éxtasis de santa Margarita de Cortona, que se encuentra en el Palazzo 
Pitti (Florencia). Aquí, el juvenil ángel es sustituido por la persona de Cristo, que, sobre un cúmulo de nubes, asiste a la religiosa franciscana.

Lo circunstancial, lo accesorio y lo artificioso son elementos recurrentes a la hora de plantear cualquier estructura escultórica, porque permiten crear situaciones subjetivas, ilusionistas, de efectos maravillosos y, en general, inexplicables. Son muchos los ejemplos, especialmente públicos (plazas, jardines, calles, etc.), los que nos ofrecen esas posibilidades visuales, no carentes de teatralidad. Representativas son las series de caballos, en actitud rampante, con o sin jinete, que demuestran todo un alarde técnico, casi siempre sobre pedestales, dominando espacios de perfil áulico. No es solo un producto de la etapa barroca, como el ejemplo de la plaza de Oriente de Madrid, llevado a cabo por Pietro Tacca (1577-1640), representando al rey Felipe IV. A tenor de las palabras del historiador Alfredo Pastor, «se trata de la primera estatua equestre con el caballo levantado sobre sus patas traseras» (Pastor 2021). Es evidente que para resolver estudios con estas particularidades, el material elegido tiene que ser el más adecuado, pues debe resistir los rigores del tiempo y de otros pormenores que suponen desgastes. El material más inmediato sería el mármol, y aunque se pueda ahuecar, no resistiría la masa y el equilibrio, sobre todo. El mármol es el material para la verticalidad. En cambio, con el metal, concretamente con el bronce, se logran esos propósitos, no solo porque resiste muy bien la intemperie, sino porque es muy versátil por sus propiedades mecánicas, de modo que el equilibrio, como centro de gravedad, queda resuelto. El escultor transforma en masa la parte trasera del caballo, dejando liberado el resto, es decir, produciendo un vacío (cera perdida) para que el animal pueda mantener sus patas delanteras elevadas, sin apoyo alguno, creando de esta manera la sensación de movimiento en plena marcha. Cada escultor había establecido su propio copyright para sorprender a los espectadores y lograr con ello su eficacia como artista. El caballo debe ser contemplado desde muchos ángulos, ocasionando distintos planos que conforman una secuencia visual. Estos recursos se han mantenido hasta nuestros días; recordar, al menos, los impresionantes caballos alocados, salvajes, de Juan José Oliveira (1928-2002) que se encuentran en la plaza de España de Vigo. Estos caballos ascienden por una cascada en forma de espiral que alcanza los $20 \mathrm{~m}$ de altura. Es una obra arriesgada, pero impresionante por los complicados escorzos, el rápido movimiento que los precipita al vacío. El agua es entonces en elemento sustentador de la narración. Igual acontece con la espectacular fuente versallesca llamada Carro de Apolo, una obra realizada por Jean-Baptiste Tuby (1635-1700). El agua del estanque sirve de límite entre los dos ámbitos -la tierra y el océano-, de modo que los caballos, ejecutados en plomo dorado, logran superar la profundidad del océano para volver a la luz. El conjunto no se entendería, como acabamos de decir, sin la presencia del agua, del estanque y, sobre todo, de los surtidores en pleno funcionamiento. Es una puesta en escena cargada de simbolismo. Los animales relinchan alborotados para vencer la masa de las aguas mientras flotan en ellas. La propia concepción de la obra, su significado y la carga alegórica aligeran la pesadez de los metales empleados, cuyo color dorado (sol) atenúa aún más si cabe la fluidez de la acción.

No es nuestro propósito ahondar en las leyes de la gravedad desde la perspectiva física, pero sí es cierto que el hombre, desde muy antiguo, siempre se pre- 


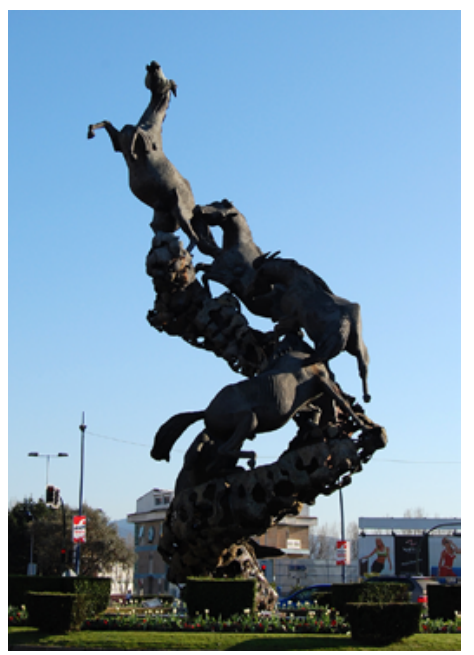

Fig. 5. Juan José Oliveira, Monumento a los caballos, 1991, $177 \times 18 \mathrm{~m}$, bronce, plaza de España, Vigo, España. https://www.turismodevigo.org/es/los-caballos, consultado el día 12 de febrero de 2021.

guntó por esta cuestión, manifestando el deseo de volar, de levitar, de descubrir la manera de mantenerse suspendido en el aire. El pintor y polifacético Leonardo Da Vinci (1452-1519), a través de sus observaciones y estudios, se atrevió a plantearlo. No lo consiguió, pero las repercusiones de este sueño tuvieron su eco durante generaciones posteriores, dando lugar a la aviación actual. El arte, en general, siempre se ha hecho esa pregunta (especialmente aquellas manifestaciones de volumen-masa): ¿cómo dominar el espacio, la gravedad, el aire? Hay manifestaciones -las acrobacias- que nos producen un estado ensońador; de igual manera danzas actuales y expresiones análogas buscan ese estado intermedio entre el cielo y la tierra. El cine, por su sorprendente capacidad técnica, ha podido demostrar que es posible llegar a ese sueño, creando situaciones prodigiosas. En la ya mítica película de E.T. el extraterrestre (1982), dirigida por Steven Spielberg, la escena del vuelo de las bicicletas es un ejemplo de ello, acreditando la eficacia de la capacidad tecnológica. Aunque el personaje de E.T. es el protagonista de la película, no cabe duda de que las distintas secuencias de las bicicletas, conducidas por Eliot (interpretado por Henry Thomas) y los amigos, constituyeron el momento de mayor tensión visual y emocional de todo el repertorio, pues supusieron para el espectador una descarga de adrenalina ante el triunfo que se avecinaba. La velocidad vertiginosa de las bicicletas, la música, los cambios rápidos de planos, el vuelo hasta el aterrizaje en el bosque trajeron consigo acrecentar el grado de emoción, sobre todo después del estado de ansiedad causado por los episodios anteriores.

La escultura también persiguió esa idea, adquiriendo más protagonismo con la llegada de las vanguardias artísticas, evolucionando en una constante búsqueda, 
como la ofrecida por Pedro Durán (Jerez de la Frontera, Cádiz), consistente en la colocación de piedras, una sobre otra, sin ningún tipo de pegamento. La condición efímera -o no- la decide el equilibrio.

Pero volviendo al pasado, especialmente a la etapa académica, los escultores no fueron muy proclives a estos experimentos, retornando una vez más al estudio de las formas para organizar la educación artística. Sin embargo, los ecos del barroco aún se dejaban notar en muchos de estos grandes repertorios, pues el lenguaje, aunque almibarado, seguía manteniéndose por mucho tiempo. Algunos modelos, sobre todo los pertenecientes a los registros mitológicos, se convierten en paradigmas del buen hacer artístico. Vuelve de nuevo el ejemplo de la Niké de Peonio a ocupar la atención de los escultores. Esta preferencia se entiende desde la concepción misma del arte. La mirada a los grandes modelos, el interés por la historia, por los artistas, por los talleres, las exposiciones, los concursos, la propia enseńanza de los centros artísticos (escuelas, academias) y la preparación más científica del docente (ya no es gremial) motivaron repetidas interpretaciones de los hitos escultóricos grecolatinos y renacentistas. Uno de los más representativos es sin duda Antonio Canova (1757-1822), que durante la primera etapa como escultor dejó entrever los ideales del barroco, especialmente en los conjuntos funerarios (tumba de la archiduquesa María Cristina. Augustinerkirche, Viena). Sin embargo, el academicismo pronto impregna toda su producción, realizando una de las Hebe más conocidas de la época moderna, que recuerda sobremanera a las citadas Victorias del pasado. Nos referimos concretamente a la que se halla en la Pinacoteca Comunale (Forsí, Italia), trabajada en mármol, y representada en el momento de servir a los dioses, de ahí que aparezca escanciando el néctar. Se nos muestra activa, atenta a las necesidades culinarias de las divinidades. La presencia es tan inmediata que todo el cuerpo de la diosa se vuelve volátil, en sutil equilibrio con «un movimiento rico di variazioni chiaroscurali créate dalle increspature delle vesti, ora sottili e quasi incise sulle superfici del corpo, ora vistosamente ondeggianti como sul retro della figura» (2003, p. 85), según palabras de Ottorino Stefani, uno de los grandes estudiosos de la obra canoviana. Y dentro de aquella generación de artistas neoclásicos, no podemos obviar escultores de la talla de Jean-Antoine Houdon (1741-1828), Bertel Thorvaldsen (17701844), que ejecutó en mármol la Joung Dansing Girl, decidida a comenzar a bailar, elevando el pie izquierdo, que se queda sin apoyo (Thorvaldsens Museum, Copenhagen, Dinamarca). Realmente la solución, como sucede en estos casos -y en los precedentes-, se encuentra en los apoyos, sutilmente inadvertidos a la vista, pero que hacen posible la firmeza de la escultura; lo mismo sucede con el Amor y Psique, de Johan Tobias Sergel (1740-1814), en el Nationalmuseum, de Estocolmo (Suecia); Gottfried Schadow (1764-1850), Franz Anton von Zauner (1746-1822), entre otros, que dejaron interesantes muestras en mármol y bronce, sobre todo, demostrando la extraordinaria profesionalidad de convertir estos materiales, aparentemente fríos y distantes, en resultados inverosímiles.

En el panorama artístico de Canarias, el periodo moderno es muy significativo, alcanzando valores universales. No es mi intensión hacer un recorrido por esa larga etapa en la que el arte fluctúa entre distintas corrientes y tendencias, pero sí detenerme en aquellas obras de mayor relevancia que se ajustan a los principios 


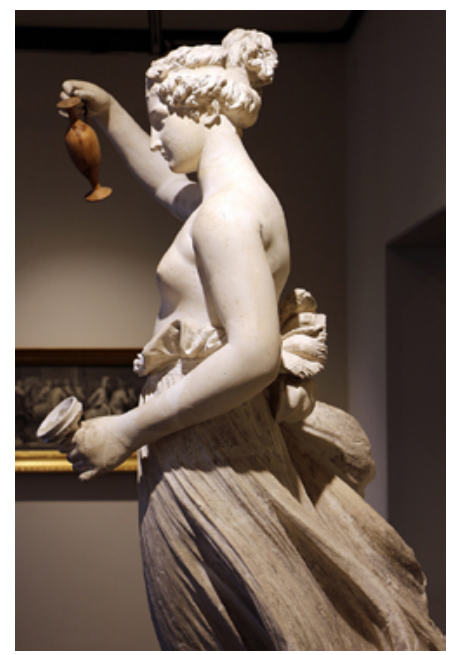

Fig. 6. Antonio Canova, Hebe, 1817, $163 \times 74 \times 82 \mathrm{~cm}$, mármol, Pinacoteca Comunale, Porsí, Italia. http://www.antoniocanova.org/hebe/, consulta hecha el día 12 de febrero de 2021.

propuestos. Es muy posible que a veces no descubramos la dimensión de una obra de arte -tampoco es tan necesario-, deteniéndonos más bien en las formas, colores, tamaños, efectos visuales o, simplemente, en el placer lúdico. Todo depende de la mirada y de las intenciones del espectador. El arte está ahí; la lectura es otra cosa. También hay obras que de tanto verlas las despojamos incluso de las emociones, ignorando cuáles fueron las premisas del escultor y cuál su mensaje. Las obras monumentales, las esculturas públicas, casi siempre reciben miradas llenas de prejuicios. Todo queda en la complacencia de la mirada. Estamos acostumbrados a la verticalidad de la obra, a la obra absoluta, icónica, conmemorativa y, en todo caso, al conjunto narrativo. Sin embargo, cada escultura tiene su propia esfera de poder que supera los propios límites de la materia, de cualquier materia, lejos ya del mármol o el bronce, como la utilización de la malla metálica que permite precisamente que la escultura supere su propio volumen. Y me refiero a la llevada a cabo por Manuel González Muñoz (+ 1965) que forma parte del conjunto artístico de la Real Academia Canaria de Bellas Artes de San Miguel Arcángel (Santa Cruz de Tenerife). No sé si se podría hablar de modalidad escultórica, pero lo cierto es que el citado material, con todas sus variantes, ha entrado a formar parte de la creatividad, de otras conductas escultóricas. Podemos hablar de los impresionantes retratos elaborados por el surcoreano Seung Mo Park, o los trabajos de José Luis Rayos y Pilar Roldán, en Espańa. Nos sorprende muchísimo contemplar una obra de estas características y, sobre todo, cuando esa obra representa a un personaje de la cultura clásica, un dios, siendo el mármol, en alto porcentaje, el material elegido para su factura. Son códigos que determinan nuestra manera de pensar y de percibir lo que vemos. 


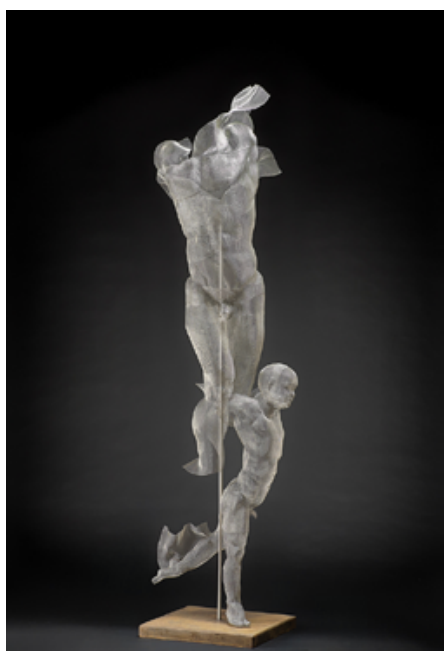

Fig. 7. Manuel González Muñoz, San Miguel Arcángel versus Apolo-Dionisos, 1763, $177 \times 105 \times 70 \mathrm{~cm}$, malla metálica de acero inoxidable, Real Academia Canaria de Bellas Artes de San Miguel Arcángel, Santa Cruz de Tenerife, España.

Fotografía de Efraín Pintos Barate.

González Muñoz supo establecer, de una manera magistral, la simbiosis entre el arcángel san Miguel y el Apolo-Dionisios. Bien es cierto que por su ligereza, la malla metálica es capaz de organizar figuras que den la sensación de ingravidez, de flotación y de movimiento. Pero no es menos cierto que el referido material, debido a la estrecha red de cuadrículas, logra una sucesión de transparencias por las que la luz, en su fluir, todo lo vuelve etéreo. Indudablemente, el citado artista «concilia lo clásico con lo contemporáneo» (González, Pintos y Álvarez 2015), fruto de su formación filosófica y cultural.

Uno de los escultores canarios que han sabido transmitir en sus obras la percepción de la fuerza interna a través de los materiales (piedra, metales, madera, etc.) es Manuel Bethencourt Santana (1931-2012). Esa intensidad concentrada permite que la materia pierda pesadez, y a pesar de los puntos de apoyo, la obra se expresa con dinamismo propio. Me gustaría citar, dentro de su amplísima producción, una pieza que a todos nos llama la atención por su aerodinamismo, titulada Milagro, y que forma parte, asimismo, de la colección artística de la mencionada Academia de Bellas Artes. No es otra cosa que la interpretación del nacimiento de un nińo; la dificultad, el dolor y el gozo que supone el parto. Este tema concreto ha estado siempre en la mente de los artistas por el profundo y ancestral significado, como también la maternidad, aunque bastante sublimada. En la sociedad azteca nos encontramos con representaciones de esculturas femeninas dando a luz (la diosa de la procreación, Tlazoltéotl), como también en otras culturas como la inca, maya, egipcia y romana. Pinturas y relieves nos informan de este acontecimiento. No obstante, el arte contemporáneo ha sido más propenso a abordar este tema de una manera más 


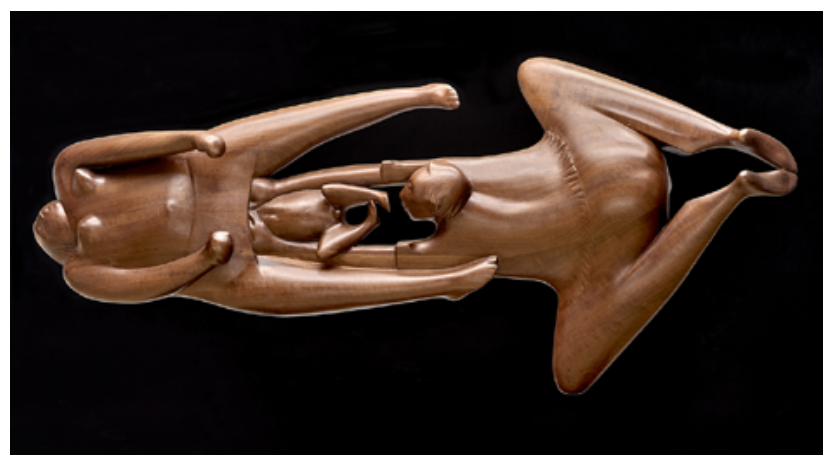

Fig. 8. Manuel Bethencourt Santana, Milagro, 1968, $70 \times 140 \times 27 \mathrm{~cm}$, madera de ukola, Real Academia Canaria de Bellas Artes de San Miguel Arcángel, Santa Cruz de Tenerife, España. Fotog.: Efraín Pintos Barate.

amplia, siendo la fotografía y el cine sus mejores aliados. Los escultores no se quedaron rezagados, aportando subjetivos y elocuentes testimonios del milagro de la vida. En el ámbito de Canarias, no podemos olvidar la interesante serie titulada Maternidad, de Eladio González de la Cruz, en la que incluye varias piezas realizadas en bronce y piedra artificial figurando este natural suceso.

En la escultura que nos ocupa, en cambio, Bethencourt no representa una escena convencional y cotidiana, sino que convierte la acción en una cosmovisión de la vida, situándola en un espacio etéreo, sin interrupción alguna, de modo que los personajes no están sujetos a nada, sino flotando en el vacío en sentido horizontal, y, como afirma Laiglesia (2018), «supone haber dado vueltas a la escultura en el aire sopesando sus ejes de gravedad para imaginar cuál podría ser su postura mejor». La madera de ukola (caoba de África) en su color natural, su textura, brillo, tonalidad marrón anaranjada y su suave superficie incrementan la nítida lectura de la composición.

Algunos de sus personajes los somete a un desafío en el aire, creando una situación realmente inquietante. De todas estas obras cabe citar una representación de Cristo, realizada en bronce (1987), en la que el Redentor se halla clavado en una cruz imaginaria, y con el brazo derecho suspendido. Solo los pies se apoyan en un pedestal de mármol. Es una versión más de la tradicional iconografía religiosa hispana, tanto en pintura como escultura, de esta curiosa figuración del Crucificado, que responde a cuestiones milagrosas, devocionales, historias legendarias y a una fecunda literatura piadosa. A partir del gótico, este tema cristológico fue muy difundido, siendo el barroco el más receptivo para su divulgación.

Sin embargo, la obra en la que Bethencourt demostró dominar el aire, el espacio público, la ingravidez, es el conocido conjunto Atis Tirma (parque Doramas, Las Palmas de Gran Canaria), que relata el suicidio de Tasarte y Benjui, en Ansite (sur de Gran Canaria), hecho ocurrido en 1479. Realmente, es una escena muy teatral, desbordada de dinamismo, de acción y no carente de dramatismo. Ambos aboríge- 


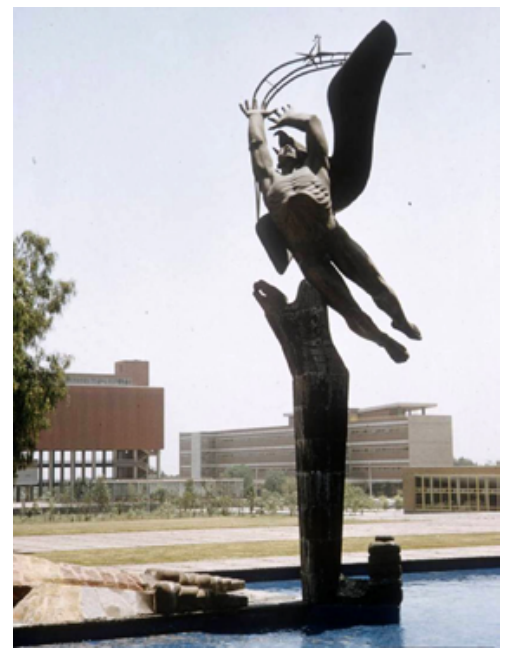

Fig. 9. Rodrigo Arena Betancourt, Prometeo de Quetzalcóatl, 1951-1952, 15 m, bronce, Ciudad Universitaria, Ciudad de México.

https://www.gaceta.unam.mx/prometeo-y-quetzalcoatl-encadenados/, consultado el día 12 de febrero de 2021.

nes caen vertiginosamente al vacío. El escultor crea un rápido e ilusorio movimiento visual en la colocación de ambos héroes, a la manera de fotogramas, de modo que el espectador consigue organizar la secuencia de la caída que comienza con la fuerza y energía del personaje de la pértiga, "una línea muy característica de Bethencourt, aunque en este caso haya prescindido de la excesiva simplicación con la que generalmente dota a sus figuras» (Quesada Acosta 2008). Descubrimos un cierto paralelismo con otros artistas y con otras obras que buscan lo mismo: el dominio del espacio, del vacío. El colombiano Rodrigo Arenas (1919-1995) es tal vez el más representativo en este tipo de obras, llegando incluso al delirio de la conquista; enormes obras en bronce presiden espacios públicos con arrolladores caballos, figuras mitológicas, protagonistas de la historia, etc., que avanzan, se retuercen en sí mismos con arrebatadora violencia, a veces como auténticos atletas que saltan al vacío; el Prometeo de Quetzalcóatl (Ciudad Universitaria. México) es un ejemplo de ello. El Titán solo se sostiene a la altura del muslo derecho anclado a un alto pedestal. El cuerpo se arquea balanceándose de un lado a otro, suscitando la sensación de libertad.

La proliferación de una estaturia narrativa, muy demandada y reivindicada en estos últimos tiempos, destinada preferentemente a ocupar espacios públicos, ha traído consigo que los artistas multipliquen sus expectativas creativas yendo más allá de la convencionalidad, introduciendo nuevos arquetipos constructivos, materiales y elementos para lograr otros modos de expresión. 


\section{BIBLIOGRAFÍA}

Bernini, D. (2018). Vita del Cavalier gio. Lorenzo Bernino. Madrid: Forgotten books.

Quesada Acosta, A. (2008). «La escultura en el espacio urbano de Canarias», en Gaviño de Franchy, C. (ed.), Anales. Real Academia de Bellas Artes de San Miguel Arcángel. Santa Cruz de Tenerife: Gobierno de Canarias. pp. 161-183.

Franzini, E. (2000). La estética del siglo XVIII. Madrid: Visor.

González de Zarate, J.M. (1987). «Corrado Giaquinto: La Paz y la Justicia. Una lectura en base a la emblemática». Norba. Revista de Arte, Geografía e Historia, Extremadura: Universidad de Extremadura, n. ${ }^{\circ}$ 7, pp. 171-182.

Álvarez Fariña, C., González de Reimiers, A.L. y Pintos Barate, E. (2015). Patrimonio Artístico en la Academia Canaria de Bellas Artes de San Miguel Arcángel. Catálogo 2005. Santa Cruz de Tenerife: RACBA.

Hibbard, H. (1982). Bernini. Madrid: Xarait Ediciones.

Jesús, T. de (2007). El libro de la vida. Madrid: Ediciones San Pablo, t. xxix.

LAIGLESIA, J.F. de (2018). «Burbujas de piedra saltando por el aire: doce ideas sobre Manuel Bethencourt escritas en una esquina del taller", en Catálogo exposición Manuel Bethencourt. El lenguaje de la vida. Santa Cruz de Tenerife: Espacio Cultural CajaCanarias.

Pastor, A. (2021). «Paseos por la Historia del Arte. Escultura. Estatua de Felipe IV (plaza de Oriente. Madrid)». Revista Alcazaba [Internet]. Alicante: n. ${ }^{\circ}$ 105. Disponible en http://www.laalcazaba.org/paseos-por-la-historia-del-arte-escultura-estatua-de-felipr-iv-en-la-plaza-deoriente-madrid-por-alfredo-pastor-catedratico-y-doctor-en-historia/, consultado el día 12 de febrero de 2021.

Stefani, O. (2003). Antonio Canova. La Statuaria. Madrid: Electa. 
